\title{
Possible Effects of COVID-19 Pandemic on Children's Mental Health
}

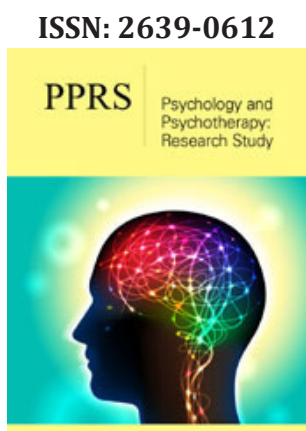

*Corresponding author: Tuğba Türkkan, Department of Social Work, Turkey

Submission: 貔June 21, 2021

Published: 此 June 30, 2021

Volume 5 - Issue 1

How to cite this article: Hatice Odaci, Tuğba Türkkan. Possible Effects of COVID-19 Pandemic on Children's Mental Health. Psychol Psychother Res Stud. 5(1). PPRS. 000604. 2021. DOI: 10.31031/PPRS.2021.05.000604

Copyright@ Tuğba Türkkan, This article is distributed under the terms of the Creative Commons Attribution 4.0 International License, which permits unrestricted use and redistribution provided that the original author and source are credited.

\author{
Hatice 0 daci $^{1}$ and Tuğba Türkkan ${ }^{2 *}$ \\ ${ }^{1}$ Departments of Psychology, Turkey \\ ${ }^{2}$ Department of Social Work, Turkey
}

\begin{abstract}
The COVID-19 pandemic, which began in China and affected the whole world, has became an urgent public health situation all over the world in a short time and has caused various reflections in the lives of individuals in terms of social, emotional, psychological and cognitive. Although the pandemic has affected individuals from all developmental stages, there has been a greater need for resources prepared for children because they cannot meet their needs on their own, they have not completed their development, and they are more open and vulnerable to other mental health problems. For this reason, our aim in this study is to evaluate the effects of COVID-19 pandemic on children's mental health in line with research published in the current literature and to provide various recommendations in this context.
\end{abstract}

Keywords: COVID-19; Pandemic; Child; Mental health

\section{Mini Review}

The coronavirus disease-2019 (COVID-19) outbreak has become a global health crisis all over the world. As of March 11, 2020, the World Health Organization has declared a pandemic, stating that the virus has spread all over the World [1]. All countries have taken various measures to control the spread of the virus, and therefore people's lives have been greatly interrupted [2]. Most countries have gradually implemented various forms of isolation and mass quarantine, resulting in global restrictions that deeply affect social and professional functioning. Daily routines and social interactions have been replaced by long periods of isolation and loneliness, and with the fear of contracting the COVID-19 infection which can result in death, people have had to cope with many negative emotions such as separation from loved ones, loss of freedom, uncertainty about the progression of the disease, despair and fear $[3,4]$. In this times, schools were closed, education was suspended, exams were postponed, shopping malls, restaurants and all public areas were put under lockdown. These negativities that emerged after COVID-19 have deeply affected the mental health of individuals [5]. Children compared to adults are among the groups that are significantly affected by traumatic events such as pandemics and natural disasters, as they lack experience and skills in accessing resources that can meet their own needs independently $[6,7]$. Children are vulnerable because of their limited understanding of the incident. Because they have limited coping strategies, they are also physically and mentally unable to protect themselves from the harms of the situation. They may not be able to express their feelings like adults. In addition, disrupting daily routines such as closing schools and leaving friends can cause stress and anxiety in children [8,9].

Therefore, considering the extent of the individuals affected by COVID-19, children are more likely to suffer from crisis situations such as the COVID-19 outbreak. In fact, studies indicate that new stress factors such as disruption of daily routines, house arrest, fear of infection, social distance with peers and friends, and lack of access to educational resources create a sense of uncertainty and anxiety among children and adolescents $[10,11]$. A recent 
study in China has determined that children and adolescents experience behavioral and emotional distress due to the COVID-19 pandemic, revealing behavioral problems such as stickiness to parents, irritability and fear that family members may become terminally ill [12,13]. Anxiety, depression, sleep and appetite disorders and deterioration in social interactions are among the most common symptoms [14].

Also in a study conducted with 584 adolescents in China, it was determined that $40 \%$ of adolescents tended to have psychological problems during the pandemic, and it was recommended that local governments should make interventions to strengthen the mental health of children [15]. However, it is stated in the relevant literature that children under quarantine may experience various psychological difficulties due to separation from parents, stigma, fear of an unknown disease and social isolation [16]. In addition, the researches states that children's reactions in many traumatic situations and/or crisis situations, including pandemics, vary depending on various factors. It is stated that the level of distress in children may vary according to the nature of the traumatic event, the home environment, the socioeconomic status of the family, the health and development level of the child, the coping skill levels of the caregivers, the secondary stressors following the traumatic event and the nature of the losses [7]. Knowing the factors that differentiate children's responses and determining the amount of risk is of great importance in terms of structuring prevention studies and developing high-quality, crisis-focused intervention approaches and appropriate psychosocial support services [17].

\section{What Can Be Done To Empower Children?}

Guidelines for protecting child mental health in the pandemic are based on the basic principles of giving children confidence, informing them about the situation in age-appropriate ways and maintaining daily routines. Other guidelines include educating children about maintaining a safe personal distance and hygiene practices, acknowledging their distress and answering all their questions honestly [14]. According to studies on the subject, parents should carefully observe their children's reactions during the epidemic, be aware of reactions such as difficulties in going to sleep and having frequent nightmares; however, it is recommended that they should be a model for their children in ways to relax, exhibit positive psychological attitudes towards reducing stress, and focus attention on a more productive and positive direction [13]. In addition, parents should avoid unnecessary separation from children; if they are separated from their parents due to a quarantine situation, alternative caregivers should be found for children and they should be kept in regular contact with their parents in these times. Exposure of children to news that creates panic in the media should be avoided, positive use of social media should be supported, and the screen time of children should be monitored [18]. Also, it is stated that maintaining daily routines in the family is important for children's mental health. It is often emphasized that bedtime and mealtime routines help children feel safe. It is recommended that parents keep their children busy with various activities such as reading or drawing, board and card games, or housework, and enable them to spend time more meaningfully, in order to make it easier for children who have to stay at home under quarantine to cope with stress and distress. In addition, to help the child feel comfortable and safe, especially during stressful times, parents can use a facilitated type of communication in which they can express their children's feelings and questions. Furthermore social interactions are important for each individual, and through online interviews and messaging applications, children can maintain communication with their loved ones. Also for children with special needs, daily activity programs that can be carried out in a home environment should be prepared, excessive disruptions in their daily routines should be avoided, and their communication with their schools and therapists, if any, should be maintained $[14,19]$.

\section{Conclusion}

Since the onset of the COVID-19 pandemic, many countries around the world and people living in these countries have been affected psychologically, emotionally, physically and economically. However, children cannot protect themselves physically and mentally from the harms of the situation because their cognitive, linguistic, physical and emotional development has not yet been completed and they have limited coping strategies. However, since any difficulties they experience during childhood may adversely affect their subsequent developmental periods, children are the group that should be provided with psychological support and increased their psychological resilience during the COVID-19 process. In this context, it is necessary to make great efforts to effectively address the problems that may occur in emergencies such as the pandemic that affects the whole world and to avoid the long-term negative effects of these experiences on the psychosocial development of children. Also, studies examining the effects of COVID-19 on child and adolescent mental health are limited in the literature. It is believed that research that will prospectively assess the impact of COVID-19 and the quarantine process on the mental health of children and adolescents will be useful for developing intervention strategies that will also cover problems that may affect different age groups. In addition, comprehensive and sustainable practices that focus on the subjective needs of families will play an important role in the effectiveness of interventions.

\section{References}

1. World Health Organization (2020) WHO director-general's opening remarks at the media briefing on COVID-19.

2. Cheng V, Wong S, Chuang V, So S, Chen J, et al. (2020) The role of community-wide wearing of face mask for control of coronavirus disease 2019 (COVID-19) epidemic due to SARS-CoV-2. J Infect 81(1): 107-114.

3. Kaplan J, Frias L, Johnsen MM (2020) A third of the global population is on coronavirus lockdown-Here's our constantly updated list of countries and restrictions.

4. Ylldırım S (2020) Social-psychological view of the epidemics: Covid-19 (Corona virus) pandemic case. Turkish Studies 15(4): 1331-1351.

5. Wang C, Pan R, Wan X, Tan Y, Xu L, et al. (2020) Immediate psychological responses and associated factors during the initial stage of the 2019 coronavirus disease (COVID-19) epidemic among the general population in China. Int J Environ Res Public Health 17(5):1729. 
6. Lieberman AF, Chu A, Van Horn P, Harris WW (2011) Trauma in early childhood: Empirical evidence and clinical implications. Dev Psychopathol 23(2): 397-410.

7. Schonfeld DJ, Demaria T (2015) Providing psychosocial support to children and families in the aftermath of disasters and crises. Pediatrics 136(4): e1120-e1130.

8. Çalışkan Y (2001) Children's mental health in the COVID-19 pandemic and quarantine. Med Res Rep 3(Supp 1): 149-154.

9. Xiang M, Zhang Z, Kuwahara K (2020) Impact of COVID-19 pandemic on children and adolescents' lifestyle behavior larger than expected. Prog Cardiovasc Dis 63(4): 531-532.

10. Centre for Disease Control (2020) Helping children cope with emergencies.

11. Pagán TL, Terepka A, Duan ZJ, Piombo M (2021) Multiphasic process model of interventions: Revisiting school-based mental health provider responses to student's mental health in the wake of COVID-19. Psychological Services. Advance online publication.

12. Browne DT, Wade M, May SS, Maguire N, Wise D, et al. (2021) Children's mental health problems during the initial emergence of COVID-19. Canadian Psychology/Psychologie Canadienne 62(1): 65-72.
13. Jiao WY, Wang LN, Liu J, Fang SF, Jiao FY, et al. (2020) Behavioral and emotional disorders in children during the COVID-19 epidemic. J Pediatr 221: 264-266.e1.

14. Imran N, Zeshan M, Pervaiz Z (2020) Mental health considerations for children and adolescents in COVID-19 pandemic. Pak J Med Sci 36(COVID19-S4): S67-S72.

15. Liang L, Ren H, Cao R, Hu R, Qin Z, et al. (2020) The Effect of COVID-19 on youth mental health. Psychiatr Q 91(3): 841-852.

16. Liu JJ, Bao Y, Huang X, Shi J, Lu L (2020) Mental health considerations for children quarantined because of COVID-19. Lancet 4(5): 347-349.

17. Akoğlu G, Karaaslan BT (2020) Possible psychosocial effects of the COVID-19 and Isolation process on children. İzmir Katip Çelebi University Faculty of Health Science Journal 5(2): 99-103.

18. The National Child Traumatic Stress Network (2020) Parent tips for helping school age children after disaster.

19. Lee J (2020) Mental health effects of school closures during COVID-19. Lancet Child Adolesc Health 4(6): 421. 